Bangladesh J. Bot. 49(1): 117-124, 2020 (March)

\title{
PLANT SPECIES USED FOR BIRDLIME-MAKING IN SOUTH AFRICA
}

\author{
Luambo Jeffrey Ramarumo*, Alfred Maroyi And \\ Milingoni Peter Tshisikhawe ${ }^{1}$ \\ Department of Botany, Faculty of Science and Agriculture, University of Fort Hare, \\ Private Bag X1314, Alice, 5700, Eastern Cape Province, South Africa
}

Keywords: Birdlime-making plants, Indigenous knowledge, Soutpansberg, Vhavenda people, Vhembe Biosphere Reserve

\begin{abstract}
Plants used for making birdlime and indigenous knowledge associated with the practice in Soutpansberg region, Vhembe Biosphere Reserve, Limpopo province, South Africa have been documented. Twelve birdlime-making plant species belonging to Apocynaceae, Celastraceae, Euphorbiaceae, Loranthaceae, Moraceae and Sapotaceae families were recorded. The common species included Maytenus peduncularis (Sond.) Loyes cited by $23.6 \%$ informants, Euphorbia pulvinata Marloth (17.2\%) and Landolphia kirkii Dyer $(12 \%)$. Plant parts used were latex (50\%), fruit (34\%), root (8) and the mixture of latex and fruit $(8 \%)$. Documentation of plant species used for birdlime-making is of great interest, not only for preservation of the Vhavenda's traditional culture, but also for promoting economic subsistence, nutritional value and livelihood amongst poor and marginalized people.
\end{abstract}

\section{Introduction}

Indigenous knowledge about plant uses and processing is considered to be prevailing, adaptive, accumulative and dynamic (Dold and Cocks 2000). This wealth of knowledge presents crucial economic opportunities and transformation to the rural and marginalized communities across the globe (Siyanbola et al. 2012). More than $70 \%$ of populations in developing countries across the globe, rely on plant derived resources for their livelihoods and economic development (Maroyi 2011), including birdlime-making, medicinal and socio-cultural activities.

Birdlime refers to the adhesive and sticky substance derived from various plant materials used for trapping small birds (Tarugarira 2012). It is usually derived from latex of various plant species (Platt et al. 2012). Birds trapping is mostly done to address challenges such as livelihood, subsistence, medicinal and religious purposes (Imchen and Joglekar 2015). In many aboriginal cultural communities, the culture of birdliming serves as an important source of nutritional value (Belda et al. 2012). Birdliming activities are also considered to be widespread practices, especially in aboriginal cultural communities (McCulloch et al. 1992). Making of birdlime has been a fundamental part of traditional culture for the Vhavenda people for many decades.

As like in any other tribes across the African continent, the Vhavenda tribe mainly acquired their knowledge about birdlime-making plant species orally, through the word of mouth and cultural transmission from one generation or lineage to another (Tolossa et al. 2013). Despite different lifestyles lead by rural South Africans, local people in the Soutpansberg region still use birdlime as part of their traditional culture. There is a need to document and disseminate African biodiversity as this is a fundamental source of livelihood and cultural development (Pakia et al. 2003). But there is a dearth of information on diversity, uses and conservation status of Soutpansberg biodiversity. Most research done so far on Soutpansberg biodiversity focused on

*Author for correspondence: <luambo@ safrica.com>. ${ }^{1}$ Department of Botany, School of Mathematical and Natural Sciences, University of Venda, Private Bag X5050, Thohoyandou, 0950, Limpopo Province, South Africa. 
medicinal plant species and their phytochemical properties used as herbal medicines (Mulaudzi et al. 2011, Magwede et al. 2014). However, there was no direct study focused on plant species used for birdlime-making in that region. The current study, therefore documented plants used for making birdlime and the indigenous knowledge associated with the practice in Soutpansberg Region, Vhembe Biosphere Reserve, Limpopo province, South Africa. The information about birdlime-making plant species is of great interest, not only for the preservation of cultural traditions (Belda et al. 2010), but also for the promotion of economic subsistence and nutritional value among poor and marginalized people.

\section{Materials and Methods}

The current study was undertaken in Kutama-Sinthumule and Nzhelele villages, in Soutpansberg Region, Vhembe Biosphere Reserve, Limpopo province, South Africa (Fig. 1). Kutama-Sinthumule is located in the western region of the Makhado local municipality within the coordinates ranging from $23^{\circ} 5^{\prime} 0.065^{\prime \prime}$ to $23^{\circ} 7^{\prime} 29.712^{\prime \prime} \mathrm{S}, 29^{\circ} 39^{\prime} 58.989^{\prime \prime}$ to $29^{\circ} 48^{\prime} 44.614^{\prime \prime} \mathrm{E}$ whereas, the Nzhelele region is located on the eastern side of the same local municipality and its coordinates ranging from $22^{\circ} 52^{\prime} 43.006^{\prime \prime}$ to $22^{\circ} 55^{\prime} 32.995^{\prime \prime} \mathrm{S}, 30^{\circ} 3^{\prime} 28.285^{\prime \prime}$ to $30^{\circ} 16^{\prime} 53.212^{\prime \prime} \mathrm{E}$ (Fig. 1).

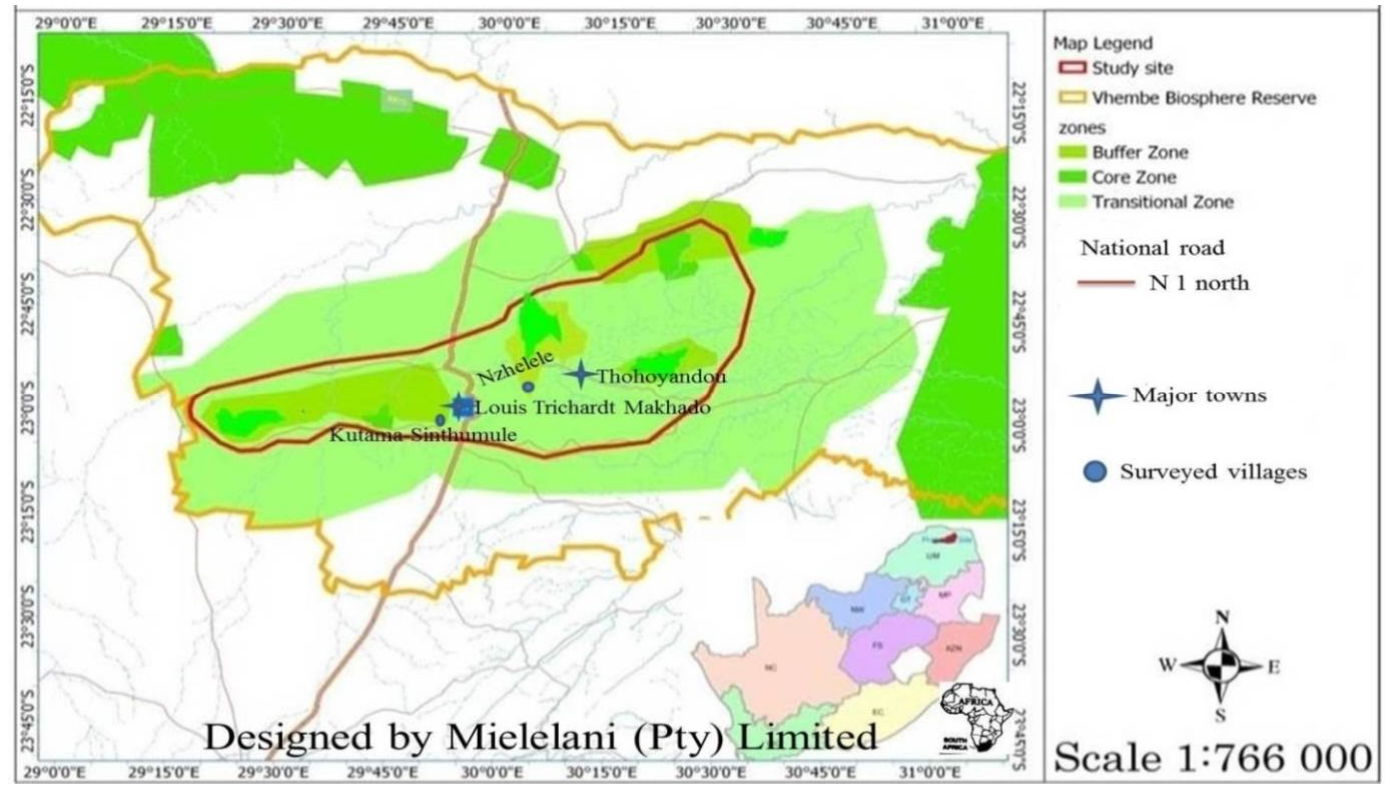

Fig. 1. Locality map of Soutpansberg.

The vegetation type within the study area is classified as bushveld of the savanna biome (Luseba and Tshisikhawe 2013). The climatic conditions of the study areas are characterized by warm-wet summer season (span from October to April) and mild-dry winter (May to September) (Gumbo et al. 2016). The regional mean annual rainfall ranged from 300 to $820 \mathrm{~mm}$ (Mpandeli 2014), with the highest rainfall received in summer season, while less rainfall is received during the winter season. The regional average annual temperatures range from 20 to $30^{\circ} \mathrm{C}$, with the highest temperature recorded in summer season (Mzezewa and Rensburg 2011). 
Documentation of birdlime-making plant species used by the Vhavenda people in the Soutpansberg region was done through participatory rural appraisal (Chambers 1994), with the informants. This study was carried out in May, 2018 until the end of September, 2018. A total of 250 informants of various age groups were arbitrarily selected. Amongst the selected informants, there were 117 laypeople, subsistence farmers (50), herbalists (30), avifaunal hunters (34) and traditional healers (19) (Fig. 2).

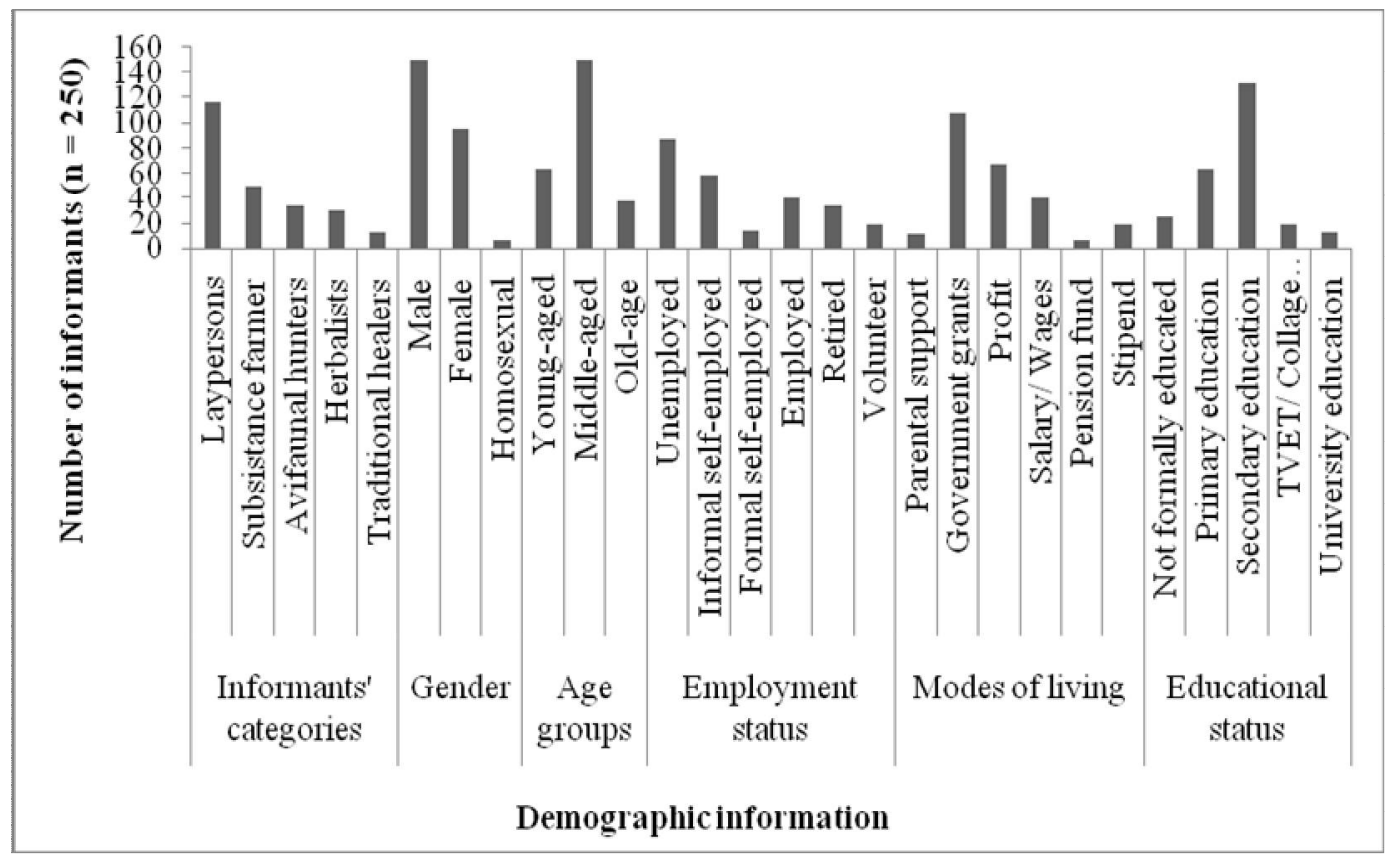

Fig. 2. Informants' biographical information.

All informants signed an informed consent form for participating in the current study, which was permitted by the University of Fort Hare Research Ethics Committee, reference number MAR031SRAM01. Information about the identities of birdlime-making plant species and traditional knowledge associated with the practice were obtained during the interview sessions with the informants using semi-structured and close-ended questionnaires (Mueller et al. 2010). To enhance the flow of ideas and participation confidence amongst the informants, interviews were carried out using local language of instruction (Tshivenda language). To avoid inconsistency and discrepancy in the administered questionnaires during the interview sessions, similar questions were administered to every informant. Field work was conducted to collect voucher specimens and validate the identities of plant species mentioned by the informants during interview sessions. The voucher collection permit was obtained from the Limpopo Department of Economic Development, Environment and Tourism, permit number: ZA/LP/92932. Data analysis was performed using Microsoft Office 2010 spreadsheet, descriptive statistical components such as, frequency of occurrence and percentage. 


\section{Results and Discussion}

The total number of 12 birdlime-making plants belonging to 5 families were recorded. According to informants, the use of various plant species in the birdlime-making has been part of the Vhavenda people's indigenous conservation strategy to reduce harvesting pressure among useful species (Personnel communication with informants). This seemed to be certain since literature suggested that ethnobotanical use of diverse plant species demonstrates wisdom, dynamism and alternatives (Kunwar et al. 2015). Amongst the recorded families, Ephorbiaceae and Loranthaceae were the most frequently utilized families with 4 species each (Fig. 3). The frequent utilization of family Euphorbiaceae and Laranthaceae was underpinned due to factors such as distribution, species diversity within these families and their abundance in the study areas. Previous studies reported that Euphorbiaceae is a diverse and largest family within the flowering

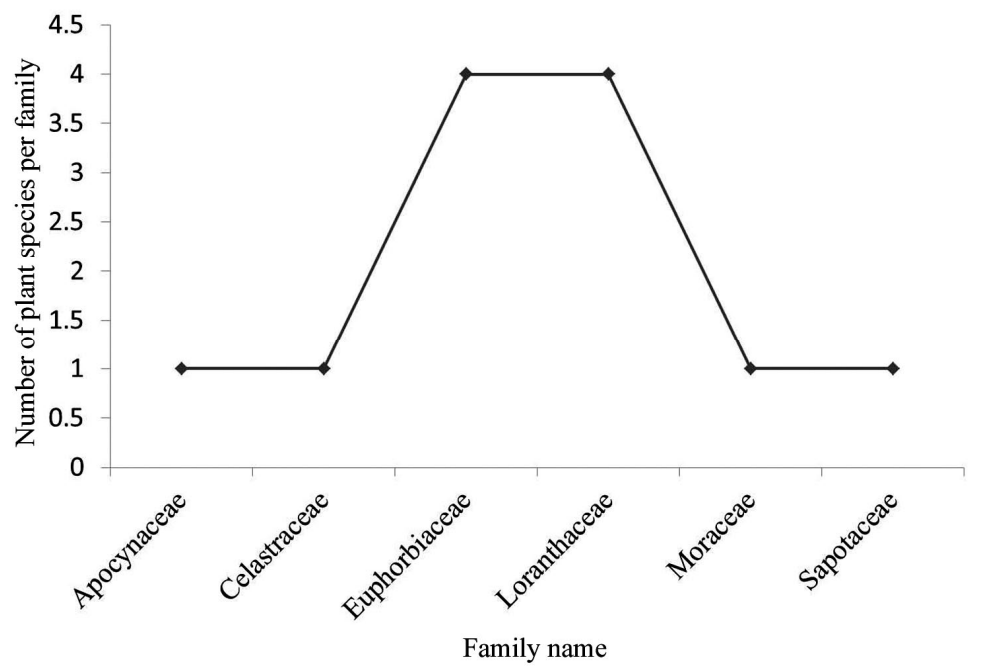

Fig. 3. Frequency of birdlime-making plant species per family.

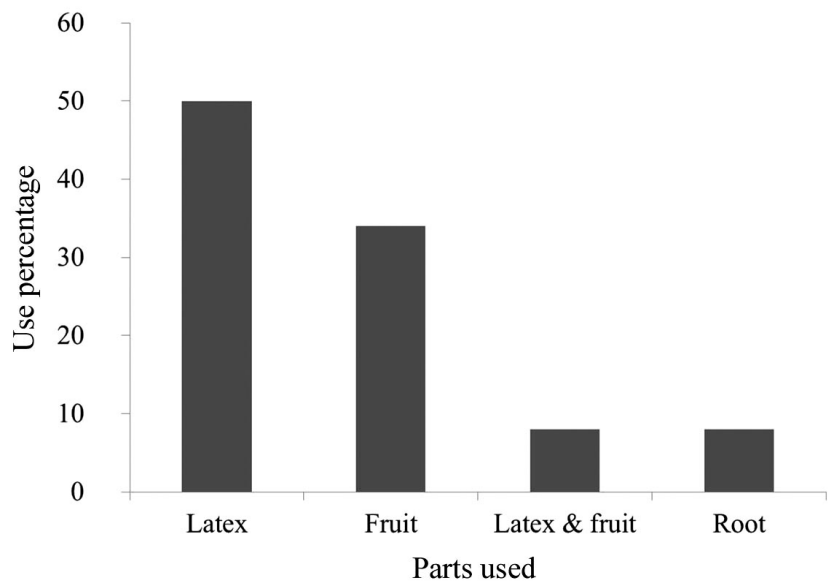

Fig. 4. Parts utilized. 


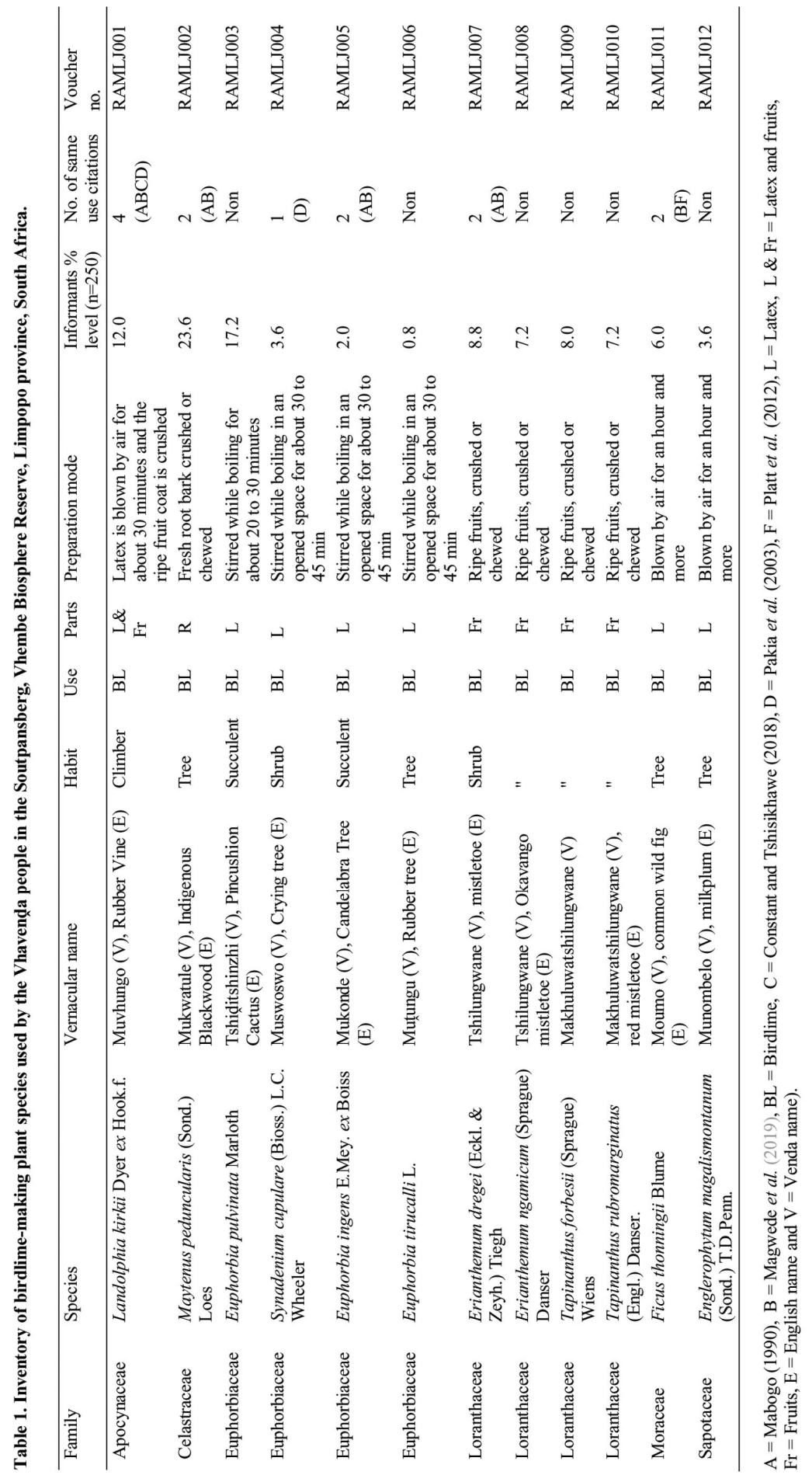


plants and it contained over 2000 species (Ernst et al. 2015), whereas, family Loranthaceae is considered to have 950 species and 77 genera (Didier et al. 2009). Among the recorded species, 6 of them were reported for being used in the birdlime-making for the first time and this included $E$. pulvinata (17.2\%), followed by $T$. forbesii (8\%), T. rubromarginatus $(7.2 \%)$, E. ngamicum (7.2\%), E. magalismon-tanum (3.6\%) and E. tirucalli (0.8\%) (Table 1). High percentage level of informants who cited M. peduncularis, E. pulvinata and L. kirkii demonstrated the certainty of common knowledge associated with their uses in the study areas (Table 1). According to the informants, it is commonly known that birdlime derived from either $M$. peduncularis or $E$. pulvinata considered to be lasting, reliable and strong if subjected to the strengthening process using latex of $L$. kirkii (Personal communication). This was supported by Magwede et al. (2018), who demonstrated that L. kirkii plays a pivotal role in the birdlime strengthening. Fig. 4, represents the utilized parts of various birdlime-making plant species. Among these plant parts, latex was regularly utilized (50\%), followed by fruit (34\%), root (8\%) and the combinations of latex and fruit (8) were equally utilized. The results of this study confoirm to the study done by Pakia et al. (2003). Although, indigenous knowledge about birdlime-making plant species seemed to be prevalent across the study areas (Fig. 5), instant transmogrified lifestyle tends to gradually erode this precious knowledge unnoticed. Mokganya et al. (2018), stated that urbanization and change in rural lifestyle can gradually erode local knowledge and traditional culture. Avifaunal hunters tend to have extensive knowledge of plants used for birdlime-making (Fig. 5). These results differ from the study done by Kayani et al. (2014), whereby laypeople were reported to have extensive knowledge about plant uses.

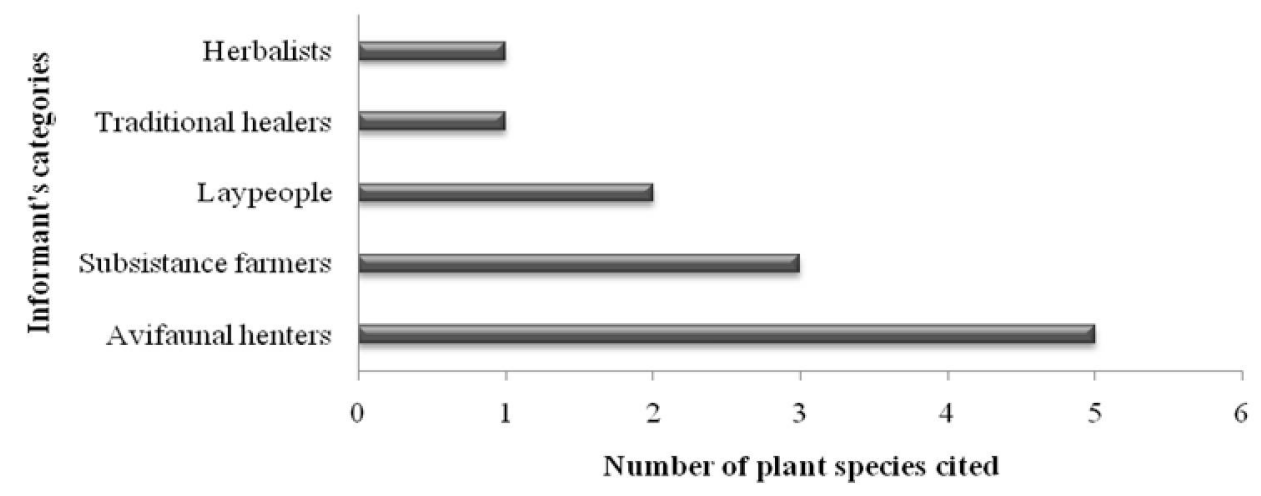

Fig. 5. Number of plant species cited per informant category.

The documentation of plant species used for birdlime-making is of great interest, not only for the preservation of traditional culture, but also for promoting economic subsistence, nutritional value and livelihood amongst poor and marginalized people. Plant species used by the Vhavenda people for making birdlime in Soutpansberg rRegion, Vhembe Biosphere Reserve, Limpopo province, South Africa yet to be fully understood. This study focused on documenting plant species used for birdlime-making by the Vhavenda people only, leaving the nutritional value and economic implications derived from birdlime-making untapped. Therefore, further studies about rural nutritional value and economic implications derived from birdliming practice are warranted. This could bring many rural communities countrywide and across the globe to the spotlight to completely understand the benefits derived from birdliming practice. 


\section{Acknowledgements}

This study was subsidized by the National Research Foundation (NRF) of South Africa, the University of Fort Hare (NRF Grant No. 112976), University of Venda and Green Empire for Biodiversity and Environmental Health Consultancy (Pty) Limited. The authors would profoundly like to thank all informants who took part in this study, including the traditional leadership (in Nzhelele and Kutama-Sinthumule Villages), who permitted the commencement of this study in their areas of jurisdiction.

\section{References}

Belda A, Martínez-Pérez JE, Martín C, Peiró V and Seva E 2010. Plants used to capture and sustain wild finches (Fringillidae) in Southeast Spain. Econ. Bot. 64(4): 367-373.

Belda A, Peiró V and Seva E 2012. The relationship between plants used to sustain finches (Fringillidae) and uses for human medicine in Southeast Spain. Evid. Based Compl. Med. 2012: 13.

Chambers R 1994. Participatory rural appraisal (PRA): Challenges, potentials and paradigm. World Dev. 22(10): 1437-1454.

Constant NL and Tshisikhawe MP 2018. Hierarchies of knowledge: ethnobotanical knowledge, practices and beliefs of the Vhavenda in South Africa for biodiversity conservation. J. Ethnobiol. Ethnomed. 14(1): 56.

Didier DS, Laurier EON, Din N, Jules PR, Victor T, Henri F, Georges S, Didier MA, Joseph BI and Akoa A 2009. An assessment on the uses of Loranthaceae in ethnopharmacology in Cameroon: A case study made in Logbessou, North of Douala. J. Med. Plant Res. 3(8): 592-595.

Dold AP and Cocks ML 2000. The medicinal use of some weeds, problem and alien plants in the Grahamstown and Peddie districts of the Eastern Cape, South Africa. S. Afr. J. Sci. 96(9/10): 467-474.

Ernst M, Grace OM, Saslis-Lagoudakis CH, Nilsson N, Simonsen HT and Rønsted N 2015. Global medicinal uses of Euphorbia L.(Euphorbiaceae). J. Ethnopharmacol. 176: 90-101.

Gumbo JR, Dzaga RA and Nethengwe NS 2016. Impact on water quality of Nandoni water reservoir downstream of municipal sewage plants in Vhembe District, South Africa. Sustain. 8(7): 597.

Imchen A and Joglekar PP 2015. Traditional Animal Hunting Practices among the Ao Nagas: A Case Study of Mangmetong Village, Nagaland. Heritage: J. Multi. Studies Archaeol. 3: 507-525.

Kayani S, Ahmad M, Zafar M, Sultana S, Khan MPZ, Ashraf MA, Hussain J and Yaseen G 2014. Ethnobotanical uses of medicinal plants for respiratory disorders among the inhabitants of GalliesAbbottabad, Northern Pakistan. J. Ethnopharmacol. 156: 47-60.

Kunwar RM, Acharya RP, Chowdhary CL and Bussmann RW 2015. Medicinal plant dynamics in indigenous medicines in farwest Nepal. J. Ethnopharmacol. 163: 210-219.

Luseba D and Tshisikhawe MP 2013. Medicinal plants used in the treatment of livestock diseases in Vhembe region, Limpopo province, South Africa. J. Med. Plants Res. 7(10): 593-601.

Mabogo DEN 1990. Ethnobotany of the Vhavenda. Thesis, Master of Science, Faculty of Science, University of Pretoria, South Africa.

Magwede K., Van Wyk BE and Van Wyk A.E. 2019. An inventory of Vhavenda useful plants. S. Afr. J. Bot. 122: 57-89.

Magwede K., Tshisikhawe MP, Luseba D and Bhat RB 2014. Ethnobotanical survey of medicinal plants used in treatment of ticks. Int. J. Exp. Bot. 83: 155-165.

Maroyi A 2011. An ethnobotanical survey of medicinal plants used by the people in Nhema communal area, Zimbabwe. J. Ethnopharmacol. 136(2): 347-354.

McCulloch MN, Tucker GM and Baillie SR 1992. The hunting of migratory birds in Europe: a ringing recovery analysis. Ibis 134: 55-65. 
Mokganya MG, Tshisikhawe MP, Swelankomo N, Tshivhandekano TR, Ramovha LI, Masevhe NA, Ligavha-Mbelengwa MH and Mocheki TA 2018. An evaluation of additional uses of some wild edible fruit plants of the Vhembe District Municipality in the Limpopo Province, South Africa. Indian J. Tradit. Know. 17(2): 276-281.

Mpandeli S 2014. Managing climate risks using seasonal climate forecast information in Vhembe District in Limpopo Province, South Africa. J. Sustain. Dev. 7(5): 68.

Mueller JG, Assanou IHB, Dan Guimbo IRO and Almedom AM 2010. Evaluating rapid participatory rural appraisal as an assessment of ethnoecological knowledge and local biodiversity patterns. Conserv. Biol. 24(1): 140-150.

Mulaudzi RB, Ndhlala AR, Kulkarni MG, Finnie JF and Van Staden J 2011. Antimicrobial properties and phenolic contents of medicinal plants used by the Venda people for conditions related to venereal diseases. J. Ethnopharmacol. 135(2): 330-337.

Mzezewa J and Van Rensburg LD 2011. Effects of tillage on runoff from a bare clayey soil on a semi-arid ecotope in the Limpopo Province of South Africa. Water SA 37(2): 165-172.

Pakia M, Cooke JA and van Staden J 2003. The ethnobotany of the Midzichenda tribes of the coastal forest areas in Kenya: 1. General perspective and non-medicinal plant uses. S. Afr. J. Bot. 69(3): 370-381.

Platt SG, Platt K., Naing TZ, Meng H, Ko WK., Lin N, Tizzard RJ, Myo KM, Soe MM and Rainwater TR 2012. Birdlime in Western Myanmar: Preparation, use, and conservation implications for an endemic bird. Ethnobiol. Let. 3: 68-75.

Siyanbola WO, Egbetokun AA, Oluseyi I, Olamade OO, Aderem, HO and Sanni M 2012. Indigenous technologies and innovation in Nigeria: Opportunities for SMEs. Am. J. Ind. Bus. Manag. 2(02): 64-75.

Tarugarira G 2012. Demystifying the indigenous language 'inadequacies' towards capacity building in science and technology in Zimbabwe. Int. J. Dev. Sustain. 1(3): 1150-1157.

Tolossa K., Debela E, Athanasiadou S, Tolera A, Ganga G and Houdijk JG 2013. Ethno-medicinal study of plants used for treatment of human and livestock ailments by traditional healers in South Omo, Southern Ethiopia. J. Ethnobiol. Ethnomed. 9(1): 32.

(Manuscript received on 11 December, 2018; revised on 6 June, 2019) 